\title{
MEASUREMENTS OF THE LONGITUDINAL MODULUS OF PIERRE CLAY SHALE AT VARYING STRAIN RATES
}

\author{
STEPHAN J. BLESS* AND THOMAS J.AHRENS
}

The propagation speed of finite-amplitude compressional waves of strain-rate $10^{3}-10^{4} \mathrm{sec}^{-1}$ in Pierre clay shale have been measured using shock wave techniques. The inferred longitudinal modulus perpendicular to the bedding is approximately a factor of four higher than that measured by others in uniaxial strain tests at strain rates of $1-5 \mathrm{sec}^{-1}$. The present shock wave speeds measured in the laboratory and in-situ finite-amplitude explosive experiments measured by others correlate more closely with field seismic velocities than with laboratory uniaxial strain measurements. Elastic properties of this highly saturated friable material measured parallel to the bedding are less sensitive to sampling disturbances than those measured in the perpendicular direction.

\section{INTRODLCTION}

The determination of constitutive properties of geologic materials for the stress range of a few to a few hundred bars is a prerequisite for accurate computational modeling of the effects of explosive-driven fields of motion. In the past, constitutive parameters of earth media often have been deduced from seismic field data and laboratory uniaxial strain and triaxial compression testing of core samples. In order to test the effectiveness of these procedures, a series of well-instrumented explosions designated as the Middle Gust free field ground motion experiments, was carried out by the Air Force Weapons Laboratory in 1971-1974 for the Defense Nuclear Agency and the Space and Missile Systems Organization of the U.S. Air Force. A description of these experiments and principal results can be found in Proceedings of the Mixed Company/Middle Gust Results Meeting (1973) and Davis (1974). ${ }^{1}$ Two

${ }^{1}$ In particular, the field data which we discuss concern a site designated as the "wet site" located at $103^{\circ} 51^{\prime} 27^{\prime}$ W. $38^{\circ} 15^{\prime} 42^{\prime \prime} \mathrm{N}$, and is taken from three explosive tests: $\mathrm{M}$ iddle Gust 3 (MG3), a surface detonation of a $1.81 \times$ $10^{5} \mathrm{~kg}$ sphere of TNT: Diskhest (DH), a surface detonation of $1634 \mathrm{~kg}$ of 400 -grain PETN primacord contained in a $30.5-\mathrm{m}$ diameter $0.3-\mathrm{m}$ high disc; and CIST9 (C9), a test sites were employed, located in Crowley County, Colo. and situated in the Cretaceous Pierre clay shale formation.

The propagation speeds of both vertically and horizontally directed finite amplitude compressional waves were well determined during the explosive test program. Propagation speeds were also predicted from the results of laboratory uniaxial strain tests conducted on vertically cored samples, from the relation $U_{s}=\sqrt{M / \rho}$, where $U_{\mathrm{s}}$ is the longitudinal wave velocity, $\rho$ is the initial density, and $M$ is the secant longitudinal modulus measured perpendicular to the bedding. In several of the horizontally bedded clay shale layers, it was found that the measured wavespeeds were two to three times higher than predicted from the uniaxial strain tests. The present work was undertaken to clarify the possible contribution of strain-rate effects and anisotropy to this discrepancy.

\section{BACKGROUND}

Constitutive properties of core samples col-

subsurface detonation of $91 \mathrm{~kg}$ of primacord in a $0.6-\mathrm{m}$ diameter by $12.2-\mathrm{m}$ deep cavity.

Contribution No. 2672, Division of Geological and Planetary Sciences, California Institute of Technology. Manuscript received by the Editor November 4, 1975 .

* Formerly. Applied Theory, Inc., Los Angeles, CA 90024; now with University of Dayton Research Institute, Dayton, OH 45469.

$\ddagger$ Seismological Laboratory, California Institute of Technology, Pasadena, CA 91125

(C) 1977 Society of Exploration Geophysicists. All rights reserved. 
lected at the test site were measured in the laboratory by the U.S. Army Engineers Waterways Experiment Station (WES) (Windham et al, 1973). Several depth intervals were distinguished in which the material properties were relatively uniform. The clay shale samples which we have studied were taken from two of these intervals.

Material I $(4.57$ to $7.01 \mathrm{~m})$ is a weathered clay shale, non- to slightly calcareous, of mean bulk density $2.27 \mathrm{~g} / \mathrm{cm}^{3}$, of mean water content 12 percent by weight of solids, and of mean air-void fraction 0.8 percent. The ultrasonic velocity perpendicular to the bedding is $\sim 2.30 \mathrm{~km} / \mathrm{sec}(\mathrm{E} . \mathrm{S}$. Gaffney, private communication, 1975). The water table was at a depth of about $1.3 \mathrm{~m}$; hence, this material was saturated in the field.

Material 2 (7.01 to $13.7 \mathrm{~m})$ is a competent clay shale, noncalcareous, with pyritic nodules and carbonate concretions, of mean bulk density 2.36 $\mathrm{g} / \mathrm{cm}^{3}$; of mean water content 8 percent by weight of solids; and of mean air-void fraction 0.7 percent. The longitudinal seismic speed, measured by a refraction survey, is $2.65 \pm .22 \mathrm{~km} / \mathrm{sec}$ (G. $R$. Skoglund, private communication, 1975). The extent to which the in-situ material is anisotropic is not well determined but appears to be slight. As measured in the (finite-amplitude) explosive tests the ratio of horizontal to vertical wave speed was $1.07 \pm .07$. However, a seismic study (Skoglund, private communication, 1975) in similar nearby material $(\sim 8 \mathrm{~km}$ distant) found this ratio to be $0.88 \pm 0.14$.

The value of strain rate $\dot{\epsilon}$ associated with the laboratory uniaxial strain measurements are in the range $1 \cdot t o 5 \mathrm{sec}^{-1}$. The strain rates appropriate to the field observations are not well defined. The accelerometer gauge records indicate rise times of $\sim 10^{-3} \mathrm{sec}$, which for strains in the range $10^{-3}$ to $10^{-4}$ imply $\dot{\epsilon} \sim 1-10 \mathrm{sec}^{-1}$. However, the instrument system used in many of the field studies strongly attenuated frequencies exceeding a kilohertz (Mixed Company/Middle Gust Results Meeting, 1973).

The dependence of elastic moduli on strain rate has been measured for several other geologic materials. For many nonporous rocks, the effect is small (Simmons and Brace, 1965; Stowe and Ainsworth, 1972; Green and Perkins, 1972). However, in porous media strain-rate effects are often quite large. In porous salt, for example, $M$ increases by 35 percent as $\dot{\epsilon}$ increases from $10^{-5}$ to $10^{5} \sec ^{-1}$ (Khristoforov et al, 1971). In sandstone from the Mixed Company site (Mixed Com-
pany/Middle Gust Results Meeting, 1973), $M$ increases by a factor of 5 between $\epsilon \sim 10^{-4}$ and $\sim 10^{5}$ sec ${ }^{1}$ (Peterson and Erlich, 1972). A Pierre clay shale almost identical to our material 2 (mean bulk density and air-void content $2.38 \mathrm{~g} / \mathrm{cm}^{3}$ and 1.0 percent) has been studied under triaxial compression at two strain rates (Knott, 1973), $\dot{\epsilon} \sim$ $10^{-5}$ and $\sim 5 \mathrm{sec}^{-1}$, between which $M$ may be deduced to have more than doubled.

There has also been some controversy over the dependency of seismic wave speed $V_{p}$ on frequency in Pierre clay shale. Ricker (1953) found $V_{p}$ increased as the square root of frequency, while McDonal et al (1958) found that $V_{p}$ was independent of frequency over the range $10^{2}$ to $10^{4}$ $\mathrm{Hz}$. The mean value of $V_{p}$ in McDonal et al's study was about $2.1 \mathrm{~km} / \mathrm{sec}$.

Wuenschel (1965), using a causal theory of wave propagation (Futterman, 1962) found the data of McDonal et al (1958) wis best fitted by a model in which $V_{p}$ increased as the logarithm of frequency; at frequencies above $100 \mathrm{~Hz}$ the phase velocity increased by the nearly constant increment $\sim 0.7$ percent per octave in frequency.

\section{EXPERIMENTS}

The objective of the present experiment was to measure the longitudinal wave speed for one-dimensional strain for strain in the range $10^{-3}$ to $10^{-2}$ for a representative series of Pierre shate samples, along different orientations, while preserving the in-situ water content. Target dises for the laboratory shock wave experiments, 4.7 to 7.7 min thick, were cut from $\sim 54$ and $\sim 128 \mathrm{~mm}$ diameter core samples, which had been coated in

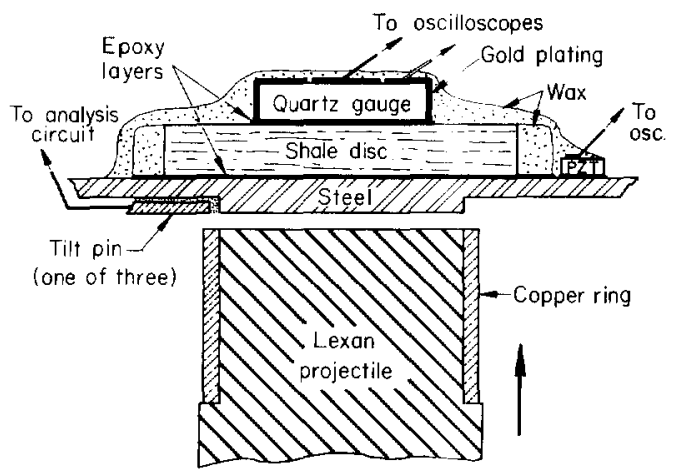

Fig. 1. Experimental configuration. Assembly shown was sealed in potting compound. 
wax immediately following extraction from the ground. During target fabrication, when the surfaces of the target disc were exposed to air, they were kept wet. The sides of the target discs in most cases were never exposed, the original wax coating remaining intact during the target-fabrication process.

The impact configuration was designed so as to provide a geometry for which the compression would be closely one-dimensional (Figure 1). A gas gun-launched projectile strikes a metal driver plate, producing a shock wave, which passes through the driver into the rock, but is severly attenuated due to the large impedance mismatch at the rock-driver interface.

The projectile velocity was determined by means of a laser system, in which the projectile consecutively interrupted three laser beams. From transit and shadow times, five measurements of projectile velocity were usually obtained. These data were averaged and the standard deviation was negligible in all cases. The stress produced in the rock target $\sigma_{r}$ was computed from the projectile velocity $U_{p}$ by an impedance formula,

$$
\sigma_{r}=\frac{2 Z_{d} Z_{r} Z_{p} U_{p}}{\left(Z_{p}+Z_{d}\right)\left(Z_{r}+Z_{d}\right)},
$$

where $Z_{d}, Z_{r}$, and $Z_{p}$ are, respectively, the impedance of the driver $(464 \mathrm{kbar} / \mathrm{km} / \mathrm{sec})$, the rock impedance $\left(\rho U_{S}\right)$, and the projectile impedance measured to be $26 \pm 2 \mathrm{kbar} / \mathrm{km} / \mathrm{sec}$ for the $1.20 \mathrm{~g} / \mathrm{cm}^{3}$ lexan projectiles, and taken as 15 $\mathrm{kbar} / \mathrm{km} / \mathrm{sec}$ for polyethylene projectiles (c.f., van Thiel et al, 1967).

Impact planarity was determined by closure of electrical contact tilt pins which were lapped flat with the impact side of the driver plate. A rrival of the shock wave at the rear surface of the driver plate and the back of the target was detected by means of a small PZT transducer and a $25.4 \mathrm{~mm}$ diameter, $6.4 \mathrm{~mm}$ thick $x$-cut quartz transducer (Ingram and Graham, 1970). A typical quartz gauge record is reproduced in Figure 2.

The shock velocity in the target was computed from the first signal arrival at the quartz gauge. In the analysis, the orientation of the projectile face at impact and the relative position of the sensing area of the gauge were taken into account. In most experiments, the fiducial arrival time measured by the $P Z T$ transducer provided a check on the impact analysis. The rise time of the signals from the quartz gauges could be satisfactorily explained by shock tilt, with a smaller contribution

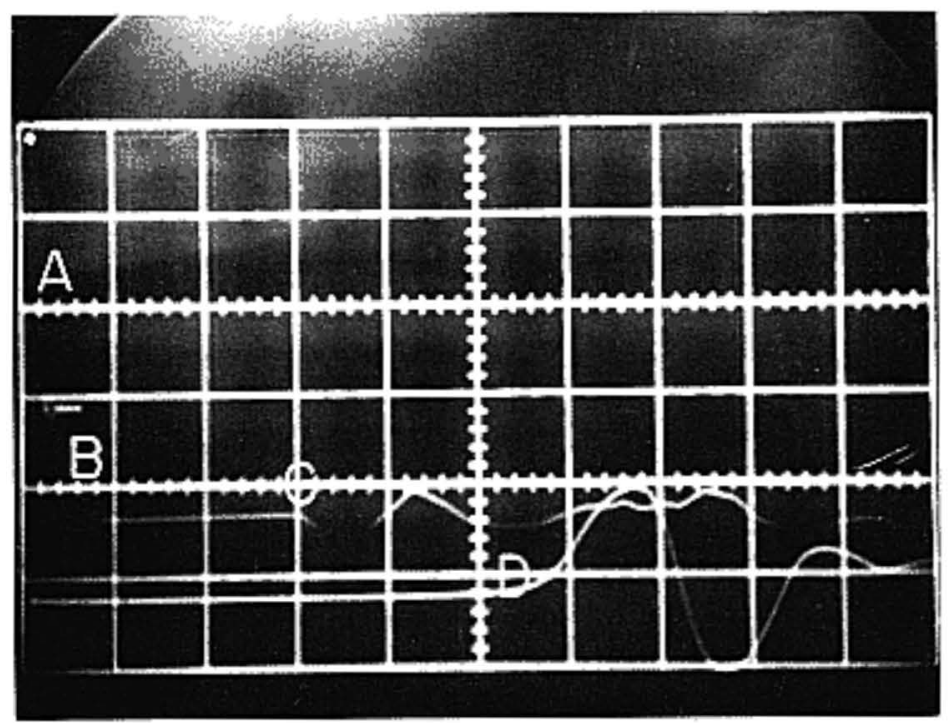

FIG. 2. Experimental record from shot RS4. Upper beam records closure of tilt pins and voltage across $P Z T$ transducer mounted next to target. Lower beam displays voltage across quartz gauge. Time scale (abscissa) is $1 \mu \mathrm{s} /$ div. Impact tilt in this shot was $0.16^{\circ} . A$ and $B$ indicate tilt pin closure, $C$ indicates the arrival of the shock at the driver back surface, and $D$ indicates the arrival of the shock at the quartz transducer. 
Table 1. Experimental results.

\begin{tabular}{|c|c|c|c|c|c|c|c|c|}
\hline Shot designation & RSI & RS2 & RS3 & RS4 & RS5 & RS6 & RS7 & RS9 \\
\hline Depth (meters) & 13.7 & 6.1 & 13.7 & 6.1 & 7.6 & 10.7 & 12.2 & 11.0 \\
\hline Material & Clay shale & Clay shale & Clay shale & Siltstone & Clay shale & $\begin{array}{c}\text { Clay shale } \\
\text { parallel } \\
\text { to bedding }\end{array}$ & Clay shale & $\begin{array}{l}\text { Clay shale } \\
\text { with } \\
\text { pyrite }\end{array}$ \\
\hline Bulk density $(\mathrm{g} / \mathrm{cc})$ & & $2.30 \pm 0.04$ & $2.39 \pm 0.02$ & & $2.30 \pm 0.05$ & & & \\
\hline $\begin{array}{l}\text { Water content (\%) } \\
\text { (by weight of solids) }\end{array}$ & & $8.4 \pm 0.1$ & $6.0 \pm 0.1$ & & $7.1 \pm 0.1$ & & & \\
\hline $\begin{array}{l}\text { Ultrasonic velocity in } \\
\text { adjacent material } \\
(\mathrm{km} / \mathrm{sec})\end{array}$ & & & $2.40 \pm 0.01$ & & $0.45 \pm 0.05$ & & & \\
\hline Target thickness $(\mathrm{mm})$ & 4.70 & 5.33 & 7.72 & 6.29 & 7.20 & 9.35 & 5.59 & 7.37 \\
\hline Projectile speed $(\mathrm{km} / \mathrm{sec})$ & 0.0645 & 0.0357 & 0.0528 & 0.0602 & 0.0466 & 0.0573 & 0.0430 & 0.0630 \\
\hline $\begin{array}{l}\text { Calculated stress (kbars) } \\
\qquad( \pm \sim 10 \%)\end{array}$ & 0.20 & 0.09 & 0.24 & 0.33 & 0.10 & 0.37 & 0.13 & 0.06 \\
\hline $\begin{array}{l}\text { Maximum measured } \\
\text { stress (kbar) }\end{array}$ & & & $\begin{array}{l}0.02 \\
\text { precursor }\end{array}$ & & & & & \\
\hline $\begin{array}{l}\text { [( ) denotes shock } \\
\text { not planar at gauge] }\end{array}$ & $(0.10)$ & - & $\begin{array}{l}0.22 \pm .02 \\
\text { shock }\end{array}$ & $(0.24 \pm 0.08)$ & - & $(0.22)$ & 0.06 & - \\
\hline $\begin{array}{l}\text { Shock velocity } \\
(\mathrm{km} / \mathrm{sec})\end{array}$ & $1.35 \pm 14$ & $1.12 \pm .13$ & $\begin{array}{l}2.81 \pm 0.25 \\
\text { precursor } \\
2.00 \pm 0.15 \\
\text { main shock }\end{array}$ & $2.49 \pm 0.25$ & $0.88 \pm 0.08$ & $2.94 \pm 0.45$ & $2.20 \pm 0.16$ & $1.04 \pm 0.05$ \\
\hline
\end{tabular}


from the shock-up times of the epoxy mounting layers.

\section{RESULTS}

The wave speeds observed in different experiments and the shock pressures calculated from the Rankine-Hugoniot equations are given in Table 1. Although measured and calculated stress are both shown in Table 1 , the calculated values are believed to be more reliable, since the quartz-gauge data are compromised by the geometry of the shock fronts, which are not parallel to the gauge faces. The density and water content were in the range observed by previous investigators. The impact tilt ranged from 0.11 degrees to 0.22 degrees.

The strain-rates associated with the stress waves can be roughly estimated from the quartz gauge records, using the approximation $\dot{\dot{\epsilon}} \approx$ $\left(2 \sigma_{r}\right) /\left(\rho T U_{s}^{2}\right)$, where $T$ is the rise time corrected for the shock tilt: the assumption is made that one-half of the time $(T)$ is due to shock-up of the epoxy layer between the gauge and rock. The five experiments from which sufficient data are available yield values of $\dot{\epsilon}$ in the range $2.5 \times 10^{3}$ to 7.9 $\times 10^{3} \mathrm{sec}^{-1}$. These high strain rates undoubtedly result from the small propagation path lengths of the present experiments.

The low wave speeds observed in RS5 and RS9 are attributed to relatively high porosity and pyrite nodules, respectively. The RS5 sample also exhibited atypical ultrasonic velocity, namely 0.45 $\mathrm{km} / \mathrm{sec}$.

The relatively high wave speed observed in RS6, which was shocked parallel to the bedding, exceeded the mean wave speed perpendicular to the bedding plane (plus its standard deviation). Thus, the anisotropy in wave speed as measured in the cores is probably real. However, it is now clear that the velocity as measured by us perpendicular to the bedding was too low because of damage to the cores. The measured velocity parallel to the bedding appears to be representative of the rock in situ.

\section{COMPARISON WITH PREVIOUS MEASUREMENTS AT OTHER STRAIN-RATES}

Wavespeed data for material 2 are compared in Figure 3 . The wave speeds from the explosive tests were determined from times of first arrival from accelerometer records provided by the Air Force Weapons Laboratory. The peak stress behind the explosively driven shock waves was calculated from the peak particle velocity $u_{m}$, using the rela-

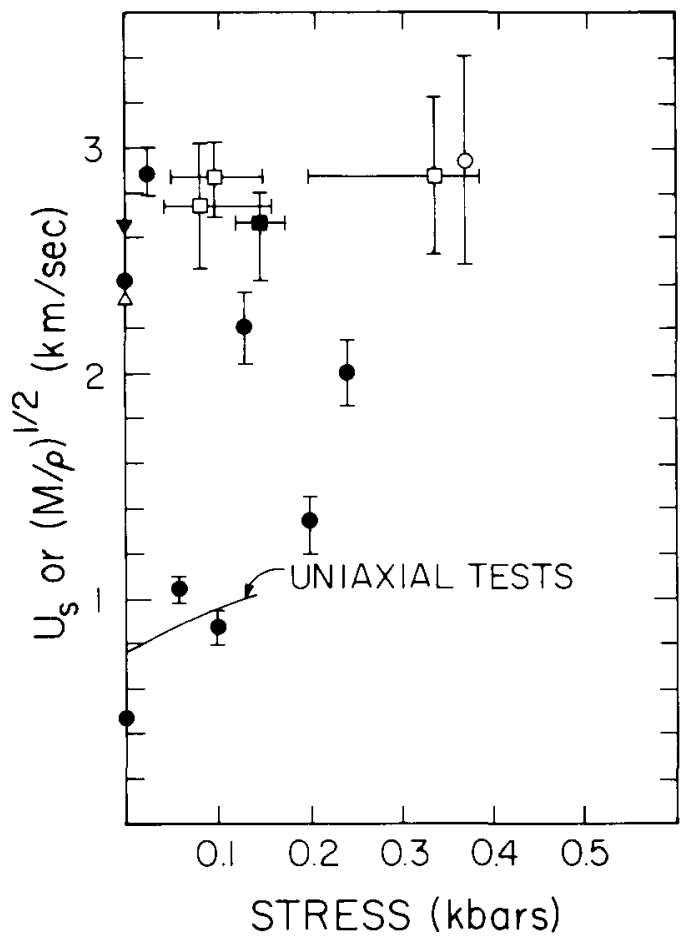

FIG. 3. Wave speeds measured and inferred in clay shale material 2: Squares show data from field high-explosive tests, circles show present data, upand down-pointed triangles are ultrasonic (E.S. Gaffney, private communication, 1975) and seismic data, respectively. Filled and open symbols indicate vertical and horizontal propagation direction, respectively. Line shows uniaxial strain test results (Windham et al., 1973).

tionship $\sigma=\rho_{0} u_{m} c$; this formula is only approximate for dispersive waves, but the relative errors arising from its use are probably smaller than the relative uncertainty in values of $u_{m}$.

If the average vertical wave speed which we have observed in material $2,1.7 \pm 0.68 \mathrm{~km} / \mathrm{sec}$, is compared with the WES value in the same stress range $(0.80$ to $1.08 \mathrm{~km} / \mathrm{sec})$, it appears that the wave speed is higher by about 80 percent at the strain rates used here than at the WES strainrates. However, such a comparison is somewhat misleading, because the WES value does not represent an average over a complete data set. Rather, an estimated fit was made to the stiffer results contained in a data set whose scatter was comparable to ours. (This was done because it was believed that "softer" cores possibly had broken during the field extraction or sample transportation/storage 


\section{Modulus of Pierre Shale}

process, and the observations reflected the closing of macroscopic cracks which did not exist in the in-situ material.) Thus, in assessing the variation of wave speed between these two data sets, shot RS9 would be better ignored, for the core employed in that shot contains large pyrite nodules and crumbled when cut. Deleting RS9 leads to an average wave speed (in the in-situ vertical direction) of $1.85 \pm .67 \mathrm{~km} / \mathrm{sec}$ over the stress range 0.024 to $0.240 \mathrm{kbars}$. The equivalent WES average is $0.94 \mathrm{~km} / \mathrm{sec}$. Thus, it appears that the difference in strain-rate between the two sets of measurements led to a difference of a factor of two apparent in wave speed.

The velocity inferred from the free field data for material from 9.1 to $18 \mathrm{~m}$ depth is $\sim 2.80 \mathrm{~km} / \mathrm{sec}$. The average wave speed which we observed in the corresponding stress and depth range (including RS6, excluding RS5 and the RS3 precursor) was $1.91 \pm .67 \mathrm{~km} / \mathrm{sec}$. Thus, as determined by the field tests, our finite amplitude experiments, and WES, average wave speeds in material 2 stand in the ratio $3.0 / 2.0 / 1.0$. If only the shock velocity in the horizontal direction is considered, the high explosive and impact tests are in essential agreement, with velocities of $\sim 2.8$ and $\sim 2.94 \mathrm{~km} / \mathrm{sec}$, respectively.

In the shallower shale comprising material 1, we have one pertinent wave speed measurement: $1.12 \pm 0.13 \mathrm{~km} / \mathrm{sec}$. The velocities observed in the field tests at this depth were $2.28 \mathrm{~km} / \mathrm{sec}$ in the vertical direction and $2.95 \mathrm{~km} / \mathrm{sec}$ in the horizontal direction. The corresponding WES velocity was $0.76 \mathrm{~km} / \mathrm{sec}$. Our second data point for material 1 (RS5) refers to a core labeled "siltstone", which appeared to the eye to be identical with the clay-shale samples. However, our measured wave speed of $2.49 \mathrm{~km} / \mathrm{sec}$ was much higher than the value obtained for material 1 shale.

\section{DISCUSSION}

Our data demonstrate that the effects of strainrate on wave speed could account for at least half, but not all, of the Middle Gust anomaly. The contribution of strain rate could also be less than we have observed for two reasons: (1) The strainrate characteristic of the field tests are less than those in our experiments, and the dependence of $M$ on $\dot{\epsilon}$ may be such that there is little change in $M$ between the WES rates and the field test rates. (2) The sensitivity of wave speed to strain-rate probably increases with void content, and to the extent that the in-situ material contains less air filled porosity than the core samples, 1 he in-situ properties may be less sensitive to strain-rate.

The relatively large anisotropy in wave speed observed in the laboratory also suggests that the in-situ material contains less air-filled porosity than the core samples. The fact that the wave speed is greater in the horizontal direction seems to imply that any cracks which open are mainly oriented in the horizontal direction (parallel to the bedding planes). Such cracks are observed to open on a macroscopic scale within 5 to $10 \mathrm{~min}$ utes after core sample sides are exposed to air. Moreover, the horizontal wave speed we measured is comparable to that seen in the in-situ material. Thus, a very important practical conclusion to be drawn from these data is that testing parallel to the bedding should be part of any program designed to derive in-situ properties of horizontally layered sedimentary rocks from measurements on core samples.

Our results can be combined with those described by Knott (1973) (in which an almost identical clay shale was studied) to show the probable variation of $M$ over ten decades of $\dot{\epsilon}$. Thus between $\dot{\epsilon}=\sim 5 \times 10^{-4}$ and $\sim 2 \mathrm{sec}^{-1} \partial \ln M / \partial \ln \dot{\epsilon}$, is $\sim 0.1$, whereas between $\sim 2$ and $\sim 5 \times 10^{3} \mathrm{sec}^{-1}$ $\partial \ln M / \partial \ln \dot{\epsilon}$ is $\sim 0.5$. It is apparent that the relative increase in $M$ per decade of $\dot{\epsilon}$ is not constant. It would be very interesting to have more data in the range 10 to $10^{3} \mathrm{sec}^{-1}$, in order to determine if the transition from "low" to "high" strain-rate behavior occurs within a relatively narrow strainrate interval.

Perhaps the most important result to emerge from this study is the general agreement between shock and elastic velocities in these clay shales. In the field studies, the seismic wave speeds agree with the shock velocities within the scatter of the data. Similarly, in core samples the ultrasonic wave speeds appear to correlate with the shock velocities, both in individual cores and averaged over many samples from a given depth interval. The strain-rate in elastic waves is generally small; however, the agreement between propagation speeds of elastic waves and finite-amplitude fastrising stress waves could arise from another effect: for elastic waves of wavelength long compared to crack dimensions, the wave speed does not differ greatly from the intrinsic wave speed of the matrix material (Anderson et al, 1974). This is also true for finite-amplitude waves of rise time short enough that inward collapse of crack walls does 
not make a significant contribution to the strain associated with a given stress.

\section{ACKNOWLEDGMENTS}

We appreciate the assistance of $\mathrm{H}$. Richeson, D. Johnson, and W. Gordy in carrying out the experimental program. Discussion with Dr. J. G. Trulio was helpful. We also wish to thank Dr. Joseph Zelasko for his review of the manuscript. This work was performed under contract FO4701-71-C-0016 from the U.S. Air Force Space and Missile Systems Organization, Norton AFB, Calif.

\section{REFERENCES}

Anderson, D. L., Minster, B., and Cole, D., 1974, The effect of orientated cracks on seismic velocities: J. Geophys. Res., v. 79, p. 4011-4015.

Davis, S. E., June 1974, Middle Gust CIST events data: Air Force Weapons Lab., Albuquerque, N.M., AFWL-TR-74-137.

Futterman, W. I., 1962, Dispersive bodywaves: J. Geophy. Res., v. 67, p. 5279-5291.

Green, S. J., and Perkins, R. D., 1972, Uniaxial compression tests at varying strain rates on three geologic materials, in Basic and applied rock mechanics: K. E. Grady, editor, SME AIME, New York.

Ingram, G. E., and Graham, R. A., 1970, Quartz gauge technique for impact experiments: Proc. 5th Symp. Detonation, Office of Naval Research.
Khristoforov, B. D., Livshits, L. D., Belinskiy, I. V., and Averin, A. N., 1971, Influence of the porosity on the parameters of dynamic compression of $\mathrm{NaCl}$ : Izvestiya, Earth Phys., v. 8, p. 31-40.

Knott, R. A., 1973, Effect of loading rate on the stressstrain characteristics of a clay shale in unconsolidated-undrained triaxial compression: U.S. Army Engr. Waterways Experim. Sta., Vicksburg, Miss., Misc. paper S-73-68.

McDonal, F. J., Angona, F. A., Mills, R. L., Sengbush, R. L., Van Nostrand, R. G., and White, J. E., 1958, Attenuation of shear and compressional waves in Pierre shale: Geophysics, v. 23, p. 421-434.

Mixed Company/Middle Gust, 1973, Results Meeting: Proc., v. 2, Defense Nuclear Agency 3151 P2.

Peterson, C. F., and Erlich, D. C., 1972, Dynamic properties of rock required for prediction calculations: Stanford Research Institute, Menlo Park, Calif., Defense Nuclear Agency 3123F.

Ricker, N., 1953, The form and laws of propagation of seismic wavelets: Geophysics, v. 18, p. 10-36.

Simmons, G., and Brace, W. F., 1965, Comparison of static and dynamic measurements of compressibility of rocks: J. Geophys. Res., v. 70, p. 5649-5656.

Stowe, R. L., and Ainsworth, D. L., 1972, Effect of rate of loading on strength and Young's modulus of elasticity of rock, in Basic and applied rock mechanics: K. E. Gray, Editor, SME AIME, New York.

van Thiel, M., Kusubov, A. S., and Mitchell, A. C. (Editors), 1967, Compendium of shock wave data: Sec. B, Lawrence Livermore Lab., Iivermore, CA, UCRL 50180 .

Windham, J. E., Chisolm, E. E., Gatz, J. L., and Lewis, J. T. 1973, Material property investigation for project Middle Gust, events I, II, and III: Report 1:Subsurface exploration and laboratory test results: U.S. Army Eng. Waterway Exper. Sta., Tech. Rep. S-73-10.

$W$ uenschel, P. C., 1965, Dispersive bodywaves-An experimental study: Geophysics, v. 30. p. 539-551. 